Section Editors

David C. Spencer, MD

Steven Karceski, MD

Steven Karceski, MD

\section{Epilepsy and pregnancy}

Are seizure medications safe?
WHAT DID THE AUTHORS FIND? In their article, "Pregnancy Registries in Epilepsy: A Consensus Statement on Health Outcomes," Dr. Meador and colleagues ${ }^{1}$ summarize important information about the risks of taking seizure medications while pregnant. On the surface, the question sounds simple: if pregnant, which seizure medications would be safe? Unfortunately, the answer is not so easily found. Only through an international collaboration have doctors been able to at least come closer to answering this question.

THE HOPE REGISTRY The international Health Outcomes in Pregnancy and Epilepsy (HOPE) was established to learn more about the effects that seizure medications (also called antiepileptic drugs or AEDs) might have on the developing baby. They have collected information from around the world. Their information comes from pregnancy registries. The registries collect and organize information about women with epilepsy and the babies who were exposed to AEDs during pregnancy. There are registries in North America, the United Kingdom, Australia, Sweden, Finland, and Europe.

Although each registry differs slightly, their goal is similar: to collect information about AEDs during pregnancy. Ideally, the women with epilepsy are enrolled when they learn of their pregnancy. The pregnancy is then followed through its course. The baby is evaluated shortly after birth. The baby is then followed for a period of time afterwards to determine whether effects might have occurred that may not have been picked up right away.

In other words, the babies are evaluated for major malformations and minor malformations. Major malformations include problems with major organs such as the heart, skeleton, or brain. They can affect the way that the baby grows and develops. The significance of minor malformations is more difficult to determine: minor malformations do not seem to cause medical problems during the person's life. Therefore, most attention to date has been focused on the major malformations.

When it comes to registries, more is better. A larger number of people mean that there is much higher confidence in the results. So far, the North American registry has enrolled more than 5,500 women. The United Kingdom registry has enrolled 5,400. There are almost
1,000 in Australia, and roughly 9,000 in the European registry. Already, this information has led to a better understanding of the effects of AEDs in pregnancy.

Despite the thousands of women in these registries around the world, doctors do not yet have information on all of the AEDs. However, the registries have helped physicians understand the risks associated with certain AEDs. It is accepted that the risk of major malformations in women who are taking no medication is $1.6 \%$ to $2.1 \%$. In other words, about $2 \%$ is the lowest or usual rate of malformations. Therefore, $2 \%$ is the basis on which all studies are compared.

The North American registry has given doctors information about phenobarbital, valproate, lamotrigine, and carbamazepine. The rate of major malformations is $6.5 \%$ with phenobarbital, $10.7 \%$ with valproate, $2.7 \%$ with lamotrigine, and $2.5 \%$ with carbamazepine. Unfortunately, there is still not enough information to calculate the risks for other AEDs.

In the United Kingdom and Australia, information has emerged for valproate, carbamazepine, and lamotrigine. In the UK, the risk of major malformations is $6.2 \%$ for valproate, $2.2 \%$ for carbamazepine, and $3.2 \%$ for lamotrigine. In Australia, it is $13.3 \%$ for valproate, $3.0 \%$ for carbamazepine, and $1.4 \%$ for lamotrigine.

In the Finnish and Swedish registries, information is available for valproate and carbamazepine only. In Finland, there is a $9.7 \%$ risk of major malformation when the baby is exposed to valproate and $4.0 \%$ with carbamazepine. In Sweden, it is $10.7 \%$ for valproate and $2.7 \%$ for carbamazepine.

The authors admit that there are problems with registry data. One key problem is that not all women with epilepsy who become pregnant are enrolled in these registries. Therefore, the information may be biased. For example, what if the women who enrolled had a history of problems during previous pregnancies? They may have decided to enroll because of their concerns about having another baby with problems. In this instance, the registry data would reflect the higher rate of birth defects. The end results would be that the registry would overestimate the risk of birth defects.

Another issue is that women with all kinds of epilepsy were enrolled. There are many kinds of epilepsy, and the type of epilepsy may contribute to the overall risk. In addition, the cause of the mother's epilepsy may 
not be known in these registries. Perhaps the cause of epilepsy also is important in assessing the risk of problems in babies born to mothers with these problems.

Finally, information about confounding factors may not be known through these registries. For instance, what was the mother's diet like during the pregnancy? Did she take vitamins? Did she smoke? Did she use illicit drugs? What other medications (prescribed or over-the-counter) were used during the pregnancy? Obviously, any of these factors might influence the outcome of the pregnancy. Without studying these factors in detail, doctors may not know the exact risk of use of AEDs during pregnancy.

HOW DOES THIS INFORMATION HELP? For a woman with epilepsy who is planning on becoming pregnant, the best time to see her neurologist occurs long before she is planning to begin a family. Many issues need to be discussed. Often, the discussion focuses on two issues. The first is how seizures during pregnancy might affect the baby. The second is how the medicines might affect the baby.

Of these concerns, the first is the concern for seizures during pregnancy. Seizures that cause falls can not only injure the woman, but can also injure the developing baby. Seizures can cause bleeding into the baby's brain and changes in the unborn baby's heart rate. Seizure control, therefore, must be maintained during the pregnancy. Available information also shows that the risk of seizures during pregnancy is greater than the risk of taking medications.

The second issue is teratogenicity, or the effect that AEDs have on the developing baby. The Food and Drug Administration (FDA) has developed a scheme that identifies the risk of teratogenicity. Using this scheme, many of the older seizure medications are pregnancy category D. There is a known risk during pregnancy; however, the benefits of their use may outweigh these risks during pregnancy. The newer AEDs are pregnancy category $C$. The risks of their use during pregnancy are unknown.

DIFFICULT CHOICES When confronted with these choices, most women are understandably concerned. They are required to make a decision regarding medicines that are known to cause problems vs ones for which the risk is unknown. Of all of the AEDs, valproate has consistently been shown to cause congenital malformations, based on the information from pregnancy registries around the world (North America, the United Kingdom, Europe, Sweden, and Finland). ${ }^{1,2}$ Many physicians agree that this mediation should be avoided, if possible, during pregnancy.

For doctors, the consultation is challenging. How should the doctor best counsel a woman when she plans to start a family? In babies born to women taking no medications, birth defects occur at a rate of about $2 \%$. Older studies suggest that when a woman is taking one AED, that risk is double (4\%-6\%). ${ }^{3}$ With two AEDs, the risk is threefold $(6 \%-9 \%)$. For women taking several AEDs at the same time, the risk may be even higher. Some studies have shown up to $15 \%$ when a person is taking three or more AEDs during pregnancy.

Doctors always try to "streamline" a person's medications before pregnancy begins. This means two things. First, the doctor will try to reduce the number of AEDs to the smallest possible combination. Second, the doctor will try to reduce the dose of the medications to the least that is needed to maintain seizure control. Both measures help to reduce this risk of major malformations.

Doctors also counsel women to take folate (folic acid), a vitamin that is important to the formation of the central nervous system. Ideally, folate should be started before pregnancy occurs. It should be continued throughout the pregnancy. Because so many pregnancies are unplanned, most physicians begin counseling patients about the importance of taking multivitamins and folate long before the woman is even thinking about starting a family. Though never proven with a randomized study, folate is thought to reduce the risk of congenital malformations. There are no studies that tell physicians what is the best dose. The recommended range is anywhere from $400 \mu \mathrm{g}$ (the amount contained in a usual multivitamin) to $4 \mathrm{mg}$ of folate.

CONCLUSIONS Doctors and patients want the same thing: good information. With good information, both the doctor and the patient can make better decisions about health care. Doctors and patients want this information now. No one wants to wait; it could take years for the best information to be found. Most women with epilepsy do not want to wait all those years to be able to make a decision about what to do with their AEDs during pregnancy.

The pregnancy registries, even with their flaws, are a good way to find out the answers to the majority of these questions. Although the information is still incomplete, it is starting to tell us more about the risks of taking AEDs during pregnancy. The registries are ongoing, and, as a result, the information will continue to emerge. Doctors will continue to analyze and summarize this information so they may provide the best information for their patients.

\section{REFERENCES}

1. Meador KJ, Pennell PB, Harden CL, et al. Pregnancy registries in epilepsy: a consensus statement on health outcomes. Neurology 2008;71:1109-1117.

2. Kalviainen R, Tomson T. Optimizing treatment of epilepsy during pregnancy. Neurology 2006;67:S59-S63.

3. Yerby MS, Collins SD. Pregnancy and the mother. In: Engel J, Pedley TA, editors. Epilepsy: A Comprehensive Textbook. Philadelphia: Lippincott-Raven; 1997. 


\section{Neurology}

\section{Epilepsy and pregnancy: Are seizure medications safe? \\ Steven Karceski \\ Neurology 2008;71;e32-e33 \\ DOI 10.1212/01.wnl.0000333613.39372.f4}

This information is current as of September 29, 2008

\section{Updated Information \&} Services

References

Permissions \& Licensing

Reprints including high resolution figures, can be found at: http://n.neurology.org/content/71/14/e32.full

This article cites 2 articles, 2 of which you can access for free at: http://n.neurology.org/content/71/14/e32.full\#ref-list-1

Information about reproducing this article in parts (figures,tables) or in its entirety can be found online at:

http://www.neurology.org/about/about_the_journal\#permissions

Information about ordering reprints can be found online: http://n.neurology.org/subscribers/advertise

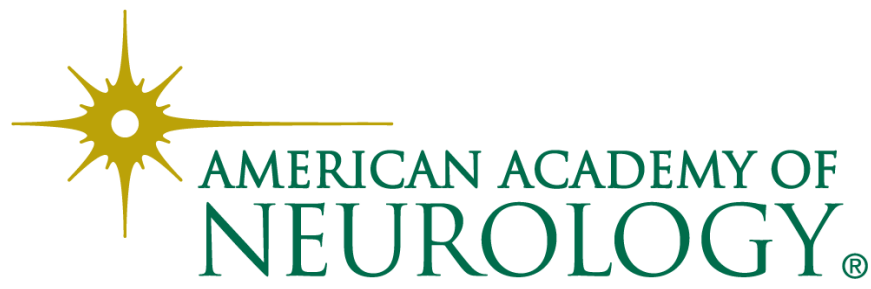

